\title{
O SIMPÓSIO EDUCAÇÃO AMBIENTAL PRESENTE NA REDE INTERNACIONAL DO CONHECIMENTO NO ANO DE 2010
}

Cláudia Battestin ${ }^{1}$

\begin{abstract}
Resumo
Este artigo apresenta e delineia a experiência e os resultados do Simpósio Educação Ambiental organizado e realizado durante o II Congresso Ciencias, Tecnologia e Culturas - Dialogo entre as disciplinas do conhecimento realizado pela Universidade de Santiago do Chile. O simpósio fez parte da programação do congresso e oportunizou aos participantes do simpósio uma verdadeira integração acadêmica por meio do diálogo e das vivencias entre os dias do Congresso.

Palavras - chave: Educação ambiental, Simpósio, Integração.
\end{abstract}

\section{Introdução}

O II Congresso Ciencias, Tecnologia e Culturas - Diálogo entre as disciplinas do conhecimento. Mirando o futuro da América Latina e Caribe ocorreu entre os dias vinte e nove de outubro e primeiro de novembro de dois mil e dez, na cidade de Santiago do Chile. O congresso foi uma iniciativa que almejou três grandes objetivos. O primeiro, contribuir ao diálogo e intercâmbio entre as diversas disciplinas do conhecimento. $\mathrm{O}$ segundo, fomentar a discussão sobre a tarefa intelectual na América Latina no marco do Bicentenário. O terceiro, gerar um grande movimento de coordenação composto por pessoas e instituições que produzem e difundem o conhecimento cientifico e intelectual ${ }^{2}$.

Diante da necessidade de discutir a problemática ambiental no âmbito educacional e da práxis pedagógica, surgiu a iniciativa de organizar e convidar professores de diferentes regiões do Brasil e também da América Latina para participarem e colaborarem na organização do Simpósio Educação Ambiental. Os professores que assumiram o compromisso em coordenar o simpósio e estiveram presentes para a efetivação do simpósio foram Cláudia Battestin, da Universidade

\footnotetext{
${ }^{1}$ Doutoranda em Educação pela Universidade Federal de Pelotas, com apoio bolsa Capes. Email: claudiabattestin@hotmail.com

$2 \mathrm{Na}$ página da Internacional do Conhecimento, (www.internacionaldelconocimiento.org) constam informações sobre os simpósios e a expressão de uma rede de conhecimentos profissionais e intelectuais. Este esforço transcende partidos, sindicatos, instituições e disciplinas, e compromete-se com a qualidade de conhecimento e honestidade intelectual, as quais são fundamentais para pensar o futuro da America Latina e Caribe.
} 
durante os dias do simpósio, foram apresentados vinte trabalhos, todos com propostas pertinentes e adequadas com a proposta do simpósio.

Conforme afirmava Freire, toda prática educativa precisa fazer uma leitura de mundo, da palavra, a partir desta prática poderemos oferecer uma "educação que proponha ou aproveite situações em que os educandos experimentem a força e o valor da unidade na diversidade" ( 2006, p. 72). Neste intuito, será apresentado o quanto cada trabalho poderá contribuir com a articulação da construção de uma vasta diversidade de ideias e projetos entre os sujeitos.

A proposta de trabalho de Aldana Telias da Universidad de Buenos Aires, abordou aspectos sobre a conformação do campo da Educação ambiental na Argentina. A autora destacou a Educação Ambiental como um campo educativo e emergente no processo de constituição e de estruturação incipiente. Já o trabalho de Benjamin Panduro Muñoz e Adriana E. Mancilla Margalli da Universidad de Colima, intitulado como "Intuición Convivencial y medio ambiente. Reacción al positivismo en México", apresentou o conceito de convivência desenvolvido por alguns filósofos mexicanos na qual possuem uma profunda preocupação com o meio ambiente. $\mathrm{O}$ artigo de Carla da Rosa Lopes da Universidade Federal de Santa Maria, com o tema "Especialização em Educação Ambiental no Ensino à Distância (EAD) da UFSM: o perfil acadêmico dos alunos sob os olhares atentos da educação" apresenta a importância do Curso de Especialização em Educação Ambiental à Distancia (EAD). O objetivo deste estudo visa identificar o perfil acadêmico dos alunos sob as perspectivas deste curso, analisando o perfil dos alunos e suas desistências, utilizando uma metodologia quantificada de dados e informações através de questionários. O trabalho apresentado pela Cibele Rosa Gracioli e Cristina Gouvêa Redin da Universidade Federal de Santa Maria, destacou a "Análise e estruturação da composição paisagística do campo de instrução de Santa Maria (CISM) para a comunidade local”. O presente estudo teve por finalidade planejar e implantar uma proposta de paisagismo dentro dos preceitos da educação ambiental técnica. A composição mais adequada segundo as observações e avaliações realizadas seria um Jardim Tropical, já que a maioria das espécies presentes são elementos utilizados nessas composições, posteriormente com identificação das espécies com o uso de placas. 
O trabalho apresentado por Cláudia Battestin da Universidade Federal de Pelotas teve como tema, "Práticas educativas ambientais: Reflexão, ação e transformação". O objetivo foi analisar a realidade global ambiental que vivenciamos nas ultimas décadas, destacando que o educador deve utilizar-se de práticas pedagógicas que desenvolvam simultaneamente valores que possam integrar culturalmente a visão planetária da crise ambiental que vivemos. Outra proposta apresentada pela mesma autora, com o título “A Educação Ambiental no Campo Filosófico: Responsabilidade e ética”, enfatiza o quanto o campo filosófico possibilita pensar e analisar as possibilidades de termos uma educação ambiental voltada a fundamentos e princípios éticos que visem a responsabilidade como uma possibilidade de mudança.

Outro trabalho apresentado por Daiane Antonio dos Santos, Larissa Barbosa e Vagner Viana Silva da Universidade Federal do Rio de Janeiro, abordou as "Hidrocidades: Ações integradas de cidadania, inclusão social e educação ambiental com vista à conservação da água em Jacarepaguá, Rio de Janeiro- Brasil’". O trabalho apresentou o Projeto Hidrocidades como possibilidade de conservação da água nos meios urbanos e periurbanos, incluindo ações integradas de cidadania e inclusão social no contexto do desenvolvimento sustentável, fomentado através da práxis de educação ambiental. A proposta de Eliana Midori Morita, Ana Maria Santos-Gouw e Marcela Fejes, Escola do Futuro - NAP/USP e Cepema/USP, intitulado "Contribuições de um encontro juvenil à educação ambiental", visou apresentar a análise de um evento de divulgação científica organizado segundo estrutura usual em congressos enquanto ação didático-pedagógica voltada para a enculturação científica na área do meio ambiente.

O trabalho de Fabíola Carvalho da Universidade Federal de Roraima, "Educação Ambiental e Formação Intercultural de Professores Indígenas”, destacou a proposta de formação de educadores ambientais em um contexto intercultural, levando em consideração a experiência prévia de cada professor, bem como a proposta de educação ambiental que cada povo já vem desenvolvendo. Por fim, a autora propõem uma reflexão sobre o papel da universidade pública nesse processo. Franco G. Knuth, Renel Prospere e Luciara B. Corrêa da Universidade Federal de Pelotas, falaram sobre "Coordenadoria de Gestão ambiental da Universidade Federal de Pelotas: Proposta de projeto de Educação Ambiental". O trabalho apresentado teve como objetivo promover a capacitação dos servidores da instituição para as questões ambientais vivenciadas nas 
atividades cotidianas de trabalho. A proposta visou promover através de um curso de Educação Ambiental na UFPel a Formação de Sujeitos Críticos e Comprometidos com a Sustentabilidade e Qualidade de Vida.

A proposta de trabalho de Jorge Orlando Cuellar Noguera da Universidade Federal de Santa Maria, apresentou a "Compostagem como prática de valorização dos resíduos alimentares com foco interdisciplinar na Educação Ambiental”. O artigo abordou aspectos sobre a compostagem como técnica a ser desenvolvida junto com temas de educação ambiental formal e informal, que possam trabalhar problemas sócio ambientais, visando analisar e discutir soluções de forma critica para una mudança de atitudes frente ao meio em que vivemos. Outro trabalho de Jorge Orlando Cuellar Noguera em conjunto com Luciana Aparecida Barbieri da Rosa, com o título: "A Educação Ambiental na Melhoria das questões sócio - econômicas ambientais dos moradores da vila Maringá - Santa Maria/ RS”, buscou através da Educação Ambiental contribuir para uma melhor qualidade de vida dos recicladores da Vila Maringá, localizada no município de Santa Maria do Estado do Rio Grande do Sul. O objetivo principal foi transmitir aos recicladores da Vila Maringá, uma aprendizagem em relação às formas de transporte, coleta e armazenagem, mostrando os lados positivos e negativos de suas atitudes, para que possam ter uma melhor qualidade de vida, visando uma vida com mais dignidade.

Macarena Cáceres Dupré da Universidad de Santiago de Chile, apresentou o "Proyecto Explora-conicyt 2009 - Midamos La contaminación atmosférica de Santiago" O projeto foi realizado a fim de incentivar a consciência ambiental dos estudantes de educação média, por meio do estabelecimento de uma rede de monitores da qualidade de ar na região metropolitana. O projeto foi patrocinado pela Universidad de Santiago de Chile (USACH) e por diversas instituições para fins de estudos estratégicos sobre energia e meio ambiente. Outra proposta importante foi apresentada por Pablo Sessano do Instituto de Investigación de Ciencias de la Educación-UBA, sobre "Educación Ambiental (EA) y pedagogías emancipadoras". O autor apresentou três aspectos sobre a configuração do campo da educação ambiental na Argentina. O primeiro refere-se a maneira em que o campo educativo interpreta a crise ambiental, o segundo, a relação entre a educação ambiental e as lutas sócio-ambientais e o terceiro, a vigência do debate 
em que se diferenciam a Educação Ambiental e a educação para o desenvolvimento sustentável.

Paulo Romeu Moreira Machado da Universidade Federal de Santa Maria, apresentou o trabalho, "Experiências e Desafios da Educação Ambiental a Distância", relatando as experiências do Curso de Educação Ambiental, da Universidade Federal de Santa Maria desde sua criação em 2008 até o ano de 2010. O autor apresentou as experiências e critérios utilizados na seleção dos alunos, além do desenvolvimento do programa acadêmico e as avaliações dos alunos matriculados no curso, bem como a forma de apresentação das disciplinas e as monografias apresentadas e defendidas.

Renel Prospere e Alfredo G. Martins da Fundação Universidade Federal do Rio Grande, apresentaram “A questão Ambiental no/do Haiti: Um desafio na reconstrução do país", abordando a necessidade da discussão ambiental no/do Haiti, pois a preservação ambiental é pouco mencionada e discutida na reconstrução desse país. Os autores apontam, por exemplo, o acelerado de consumo de madeira e carvão vegetal como principal fonte para produzir energia e ameaça transformar este pequeno país em um deserto.

O autor Rodrigo Elizalde do Grupo OTIUM: Lazer, Brasil \& América Latina (UFMG) apresentou o trabalho "Ocio Contrahegemónico: Disoñando um mundo sustentable". O objetivo da proposta foi situar o ócio na atualidade, vinculando com a necessidade de uma profunda mudança paradigmática, epistemológica, política e educativa. Simone Terezinha Dias de Oliveira e Paulo Edelvar Corrêa Peres da Universidade Federal de Santa Maria escreveram sobre "Ações ambientais com pessoas que convivem com o vírus HIV - do grupo de apoio do hospital universitário de Santa Maria - HUSM". O projeto em educação ambiental foi de caráter não formal, desenvolvido junto ao Grupo de Apoio a portadores do vírus HIV do hospital Universitário de Santa Maria, cujo objetivo é buscar através de debates e oficinas temáticas uma motivação para eleição de valores acerca do meio ambiente e uma conscientização da realidade do nosso planeta. O artigo de Tanny de Oliveira Bohner e Cibele Rosa Gracioli, também da Universidade Federal de Santa Maria, abordou a "Rotulagem das espécies arbóreas localizadas no setor de paisagismo do colégio Politecnico da UFSM". O objetivo desse trabalho foi identificar, rotular e localizar as plantas de pequeno, médio e grande porte, do grupo das árvores e de palmeiras (nativas 
e exóticas), existentes no setor de paisagismo do Colégio Politécnico da UFSM, em Santa Maria, RS, a fim de proporcionar o conhecimento das espécies.

O texto de Maria Eduarda do Nascimento Vaz Moniz dos Santos, da Universidade do Porto, apresentou o texto, "Trânsitos e conexões entre educação ambiental e cidadania ambiental" enfatizando a possibilidade da educação intervir na construção da cidadania ambiental, estimulando os cidadãos a pensarem sobre o significado e o alcance da intervenção humana na terra. José Alfredo Villagómez-Cortés e Ana Lid Del Ángel Peréz, da Universidad Veracruzana do México, destacaram as ideias sobre "O papel da parceria de instituições de ensino em sustentabilidade e preservação ecológica", explanando o quanto a deterioração ambiental é uma característica comum em todo o planeta, mas os seus efeitos parecem ser mais graves nos países em desenvolvimento. Paradoxalmente, estes países são os mais ricos em termos de diversidade biológica, bem como no tamanho e densidade de vários recursos naturais. Todavia, o poder econômico dos países desenvolvidos colocam grande pressão para tirar proveito de tais recursos para seu próprio beneficio. Por este motivo, os autores defendem a ideia de que por meio de uma parceria adequada entre as instituições de ensino e pesquisa é possível criar consciência sobre a irreversibilidade da ecologia.

O simpósio Educação Ambiental foi uma forma efetiva de mostrar o quanto é possível um diálogo entre as áreas do conhecimento, bem como uma articulação entre diferentes instituições, experiências e culturas. Além da integração entre os participantes, ocorreram trocas de conhecimentos, experiências e diferentes olhares sobre a possibilidade de pensar diferente, de fazer a diferença.

\section{Considerações Finais}

O diálogo entre as mais distintas instituições de ensino nos aproximaram do pensamento do educador Paulo Freire, pois o mesmo sempre almejou um espaço de encontro com pessoas movidas pelo sonho de um mundo mais justo e humano. Freire lutava para que os educadores de todas as áreas pudessem se reunir e contribuir para a construção de uma educação como prática libertadora, solidária e com consciência planetária. Esta consciência planetária supõe a tolerância, a equidade social, a igualdade 
III SEMINÁRII ECOLOGIA

PDLÍTICA

de gêneros, a aceitação de biodiversidade e a promoção de uma cultura da vida a partir da dimensão ética. Neste sentido, devem ser introduzidas ao debate acadêmico, questões emergentes e necessárias para a pesquisa, de maneira que possamos desenvolver competências e habilidades que visem uma orientação para o conhecimento constante e permanente no centro das investigações ético-filosóficas e educacionais.

Neste contexto Freire afirma que: "As sociedades não têm o destino de serem pouco sérias ou exemplos de honradez. Sociedades não são, estão sendo o que delas fazemos na História, como possibilidade. Daí a nossa responsabilidade ética" (FREIRE, 2006, p. 39).

Precisamos de uma Educação que problematize e mostre a importância dos sujeitos no mundo e com o mundo. Que estimule a reflexão dos sujeitos acerca das realidades vividas, sobre a alienação, a exploração do homem pelo homem, e do homem com o meio ambiente. Quanto mais problematizarmos e orientarmos os sujeitos, mais reforçaremos a necessidade de uma educação ambiental que vise a vida como prioridade. Não é considerado cabível colocar uma disciplina na grade curricular como disciplina "educação ambiental", não é com a criação desta que vamos conseguir uma transversalidade em conhecimentos e formação de sujeitos éticos. O educador Georgen vem ao encontro da ideia afirmando que:

\footnotetext{
Não é pela criação de uma nova disciplina nem que se lhe atribua características de transversalidade que irá garantir a formação de um sujeito ético, responsável pelas suas ações e consequências delas decorrentes. As formas de pensar, sentir e julgar de crianças e jovens formam-se no contato com o meio no qual elas vivem e crescem (...) A sociedade em seus diferentes ambientes, é responsável pela formação ética das futuras gerações. (GEORGEN, 2001, p. 83)
}

O professor Goergem afirma também que "a educação está novamente sendo solicitada a contribuir para superar tal crise" (2001, p. 91). Essa ideia nos faz refletir sobre as possibilidades que a educação ambiental tem para amenizar os problemas do nosso tempo, bem como, direcionar os seres humanos para um mundo digno de se viver. 


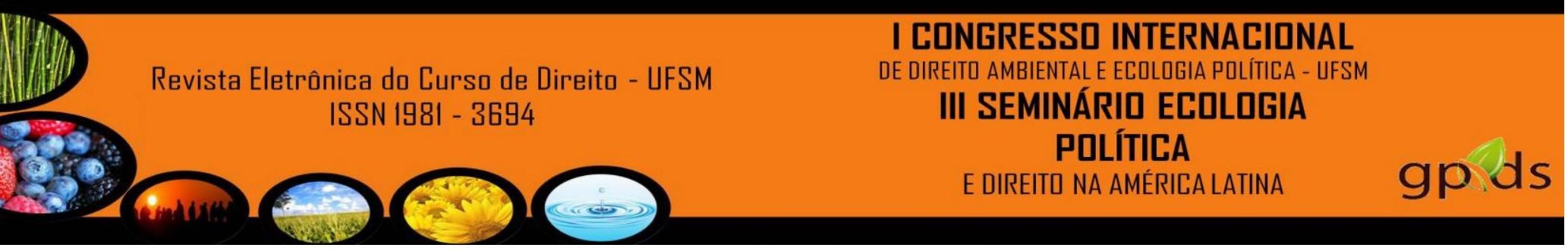

Referências Bibliográficas

FREIRE, Paulo. A sombra desta Mangueira. 8 ed. São Paulo: Olho d'agua, 2006.

Pedagogia da Indignação: Cartas Pedagógicas e outros escritos. Apresentação de Ana Maria Araújo Freire. São Paulo: Ed. UNESP, 2000.

GEORGEN, Pedro. Pós-modernidade, ética e educação: polêmicas do nosso tempo. Campinas: Autores associados, 2001. 